\title{
PENERAPAN MODEL ELICITING ACTIVITIES UNTUK MENINGKATKAN SELF EFFICACY (KEYAKINAN DIRI) DAN HASIL BELAJAR PESERTA DIDIK
}

\section{THE IMPLEMENTATION OF ELICITING ACTIVITIES MODEL TO RAISE THE SELF EFFICACY AND STUDENT'S ACHIEVEMENTS}

\author{
Rasmiwetti, Ega Fahreni*, Jimmi Copriady \\ Program Studi Pendidikan Kimia, Fakultas FKIP Universitas Riau, Indonesia \\ *Email: egafahreni08@gmail.com
}

Diterima: 2 Desemner 2019. Disetujui: 3 Desemner 2019. Dipublikasikan: 2 Maret 2020

\begin{abstract}
Abstrak: Tujuan penelitian ini adalah untuk mengetahui keefektifan model pembelajaran eliciting activities dalam meningkatkan hasil belajar siswa pada materi hidrokarbon di kelas XI SMAN 15 Pekanbaru. Penelitian merupakan jenis penelitian quasi exsperiment menggunakan rancangan randomized pretest-posttest control group. Populasi penelitian adalah semua siswa kelas XI SMAN 15 Pekanbaru, sedangkan sampel penelitian adalah siswa kelas XI MIA 2 dan MIA 3 SMAN 15 Pekanbaru. Pada penelitian ini digunakan uji normalitas dan uji homogenitas. Uji normalitas secara Liliefors yang bertujuan untuk melihat normalitas data, sedangkan uji homogenitas bertujuan menguji kesamaan varians dan uji kesamaan rata-rata dengan menggunakan uji $\mathrm{F}$ dan ujit. Uji hipotesis untuk meningkatkan self efficacy (keyakinan diri) dan hasil belajar dihitung dengan menggunakan uji-t. Hasil uji-t adalah $t_{\text {hitung }}>t_{\text {tabel }}$ yaitu 19,75 $>1,67$, dapat disimpulkan model eliciting activities dapat meningkatkan self efficacy. Sedangkan korelasi antara self efficacy (keyakinan diri) dengan hasil belajar dihitung menggunakan uji product moment. Penerapan model eliciting activities dapat meningkatkan self efficacy (keyakinan diri) dan hasil belajar. Nilai korelasi (r) nya adalah 0,8079 > 0,392, dapat disimpulkan terdapat korelasi positif yang sangat kuat antara self efficacy (keyakinan diri) dan hasil belajar siswa pada materi hidrokarbon.
\end{abstract}

Kata Kunci : Model Eliciting Activities, Self Efficacy, Hasil Belajar, Hidrokarbon.

\begin{abstract}
This research aims to know the raising self efficacy and student's achievements in grade XI Science of Senior High School 15 Pekanbaru. This research is quation experiment using randomized pretest-posttest control group design. The population in this research is students. The sample of this research isstudents in grade XI science 2 as the experimental class and XI science 3 as the controlling class after the normality and homogeneity test have done. Normality test has done using Liliefors test, to see the normality of the data amd homogeneity test has done to see the similarity variant test and average test use F and t-test, to see the sample of data wheteher it has the similarity in variant or the ability (homogeneity). Hypoteheses test to raise self efficacy and student's achievement were calculating using t-test. Whereas the correlation between self efficacy and student's achievement were calculating use product moment test. The result of this research is the implementation of eliciting activities model can improve self efficacy and student's achievement. There are positive correlation between self efficacy and student's achievement in powerful category.
\end{abstract}

Keywords : Eliciting Activities Model, Self Efficacy, Student's Achievements, Hydrocarbon.

\section{PENDAHULUAN}

Pendidikan untuk mengembangkan potensi peserta didik. Prinsip dalam pendidikan adalah pendidik tidak memberikan pengetahuan saja kepada peserta didik melainkan peserta didik yang harus membangun pengetahuannya sendiri [1]. Peserta didik merupakan penentu terjadi atau tidaknya proses belajar [3]. Mata pelajaran kimia SMA/MA bertujuan agar peserta didik mampu memahami konsep, prinsip, hukum, teori kimia dan pemecahan masalah dalam kehidupan nyata [8]. Hidrokarbon merupakan materi sarat akan konsep yang membutuhkan analisis komprehensif dan sistematis yang menuntut siswa lebih fokus dalam mengikuti proses pembelajaran.
Pokok bahasan hidrokarbon bersifat hafalan serta membutuhkan pemahaman konsep yang kuat sehingga peserta didik cenderung bosan dan kurang antusias saat pembelajaran berlangsung. Siswa kurang terlibat aktif dalam proses pembelajaran, kemauan untuk bertanya dan berkomentar, serta yakin mengemukakan pendapat yang rendah serta tidak menguasai materi yanf mengakibatkan keyakinan diri dan hasil belajar peserta didik kurang memuaskan.

Model Eliciting activities merupakan salah satu model pembelajaran yang dapat dijadikan untuk mengatasi permasalahan tersebut [12][13]. Model eliciting activities adalah permasalahan yang didasarkan pada situasi kehidupan nyata, terdiri dari kelompok kecil 3-5 peserta didik yang bekerja untuk 
memecahkan permasalahan, mengemukakan, menguji dan meninjau ulang solusi untuk pemecahan suatu masalah [4]. Penelitian yang relevan menyimpulkan hasil penelitian dengan model eliciting activities berpengaruh dengan kemampuan berfikir kreatif matematis dan self confidence terhadap mata pelajaran matematika. Hasil analisis pada uji perbedaan rata-rata menyatakan nilai kemampuan berfikir kreatif peserta didik sesudah menerapkan model eliciting activites lebih baik dibandingkan sebelum menerapkan model eliciting activities [12].

Sedangkan penelitian yang dilakukan peneliti adalah penerapan model eliciting activites untuk meningkatkan self efficacy (keyakinan diri) dan hasil belajar peserta didik. Perbedaan terletak pada variabel, bidang studi, dan lokasi penelitian. Alasan peneliti mengambil model eliciting activities karena model tersebut memiliki keunggulan yaitu memberi kesempatan yang sangat besar untuk mengeksplorasi pengetahuan dalam pembelajaran, lebih terbiasa memecahkan atau menyelesaikan soal-soal pemecahan masalah, dan mempunyai kesempatan lebih banyak dalam memanfaatkan pengetahuan serta keterampilan [2].

\section{METODE PENELITIAN}

Penelitian ini dilakukan di SMA Negeri 15 Pekanbaru yang berlokasi di Jl. Cipta Karya Pekanbaru Riau pada semester ganjil tahun ajaran 2019/2020. Jenis Penelitian yaitu penelitian quasi eksperimen dengan rancangan randomized pretestposttest control group design. Populasi dalam penelitian ini yaitu peserta didik kelas XI MIA SMAN 15 Pekanbaru sebanyak 72 orang. Teknik pengambilan sampel dengan teknik random (acak) dan teknik analsisi data yaitu menggunakan uji-t dan uji korelasi product moment. Terdapat 2 variabel dalam penelitian yaitu variabel bebas dan variabel terikat. Variabel bebas dalam penelitian ini adalah model eliciting activities. Sedangkan variabel terikat dalam penelitian ini adalah Self efficacy (keyakinan diri) dan hasil belajar.

\section{HASIL DAN PEMBAHASAN}

Pada penerapan model eliciting activities materi hidrokarbon mempunyai haisl penelitian sebagai berikut:

\section{Data Self Efficacy}

Nilai angket self efficacy diperoleh dari data skor angket self efficacy peserta didik. Angket tentang self efficacy dijawab pada saat pretest dan posttest. Pertanyaan berjumlah 34 butir yang telah disesuaikan dengan dimensi dan indikator self efficacy. Nilai angket self efficacy peserta didik dapat dilihat pada Gambar 1 berikut:

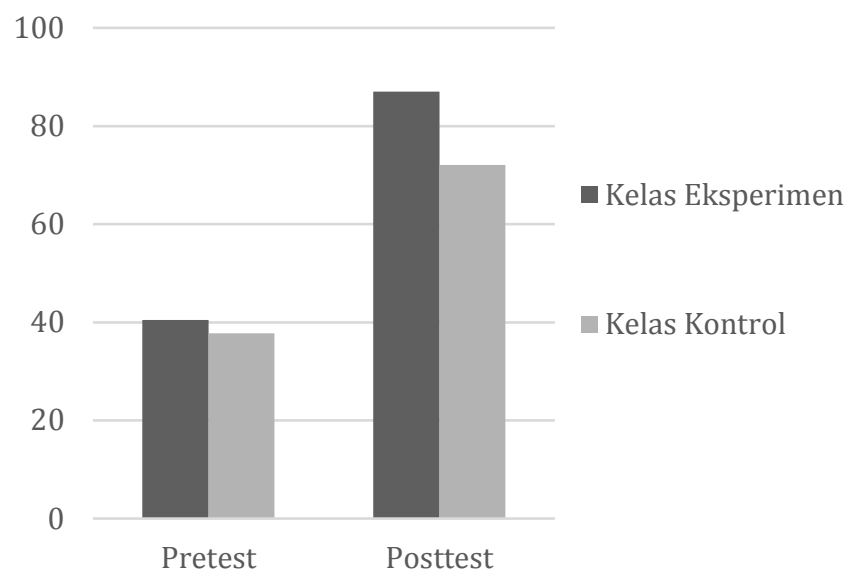

Gambar 1. Diagram peningkatan nilai self efficacy

Gambar 1 terlihat bahwa nilai rata-rata self efficacy (keyakinan diri) peserta didik kelas eksperimen disaat pretest adalah 40,44\%, tergolong kategori rendah. Sedangkan nilai rata-rata dari self efficacy peserta didik kelas kontrol disaat pretest adalah $37,75 \%$ tergolong kategori rendah. Hal ini berarti bahwa peserta didik telah memiliki self efficacy dalam diri mereka namun belum optimal. Nilai self efficacy peserta didik kelas eksperimen disaat posttest adalah 87,01\% tergolong kategori sangat tinggi. Sedangkan nilai rata-rata dari self efficacy peserta didik kelas kontrol disaat posttest adalah 72,02\% tergolong kategori tinggi. Peningkatan self efficacy (keyakinan diri) peserta didik terlihat dari nilai $t_{\text {hitung }}>\mathrm{t}_{\text {tabel }}$ yaitu 19,75 $>1,67$. Maka dapat disimpulkan penerapan model eliciting activities dapat meningkatkan self efficacy (keyakinan diri) peserta didik. Peningkatan self efficacy di dorong oleh dengan diberikannya kesempatan yang luas kepada peserta didik untuk mengeksplorasi informasi dan pengetahuan yang sudah dimilikinya dalam proses pembelajaran [5].

Kegiatan eksplorasi untuk memecahkan permasalahan mampu memberikan peluang kepada peserta didik untuk mengembangkan self efficacy (keyakinan diri). Self efficacy (keyakinan diri) inilah yang harus di stimulasi dalam proses pembelajaran, baik itu diberikan oleh guru secara langsung ataupun berasal dari kemauan peserta didik itu sendiri. Pembelajaran kelas eksperimen yang menggunakan model eliciting activities menjadikan peserta didik lebih terpacu untuk menyelesaikan permasalahan yang diberikan pada Lembar Kerja Peserta Didik (LKPD). Rasa antusias tersebut juga berimbas positif terhadap self efficacy (keyakinan diri) ketika memberikan solusi terhadap pemecahan masalah. Sejalan dengan pendapat [6] menyatakan bahwa 
adanya interaksi dari lingkungan (penerapan model) terhadap perilaku (self efficacy) dapat mempengaruhi secara positif terhadap hasil belajar (kognitif) peserta didik.

Guru dalam pembelajaran, memberikan dorongan-dorongan sosial melalui kontak fisik pembelajaran dari kelas kontrol hanya dibelajarkan dengan pendekatan saintifik tanpa model eliciting activities, porses pembelajaran di kelas kontrol belum menunjukkan hasil yang optimal terhadap self efficacy (keyakinan diri). Hal ini disebabkan proses pembelajaran tidak ada inovasi dan variasi

\section{Hasil Belajar}

Hasil belajar peserta didik di ketahui melalui perbandingan nilai pretest dan nilai posttest. Peningkatan hasil belajar terlihat dari nilai $t_{\text {hitung }}>$ $t_{\text {tabel }}$ yaitu 3,60 > 1,67. Hasil itu menunjukkan bahwa hasil belajar dengan menerapkan model eliciting activities lebih besar dibandingkan hasil belajar tanpa menerapkan model eliciting activities. Peningkatan hasil belajar dapat dilihat pada Gambar 2.

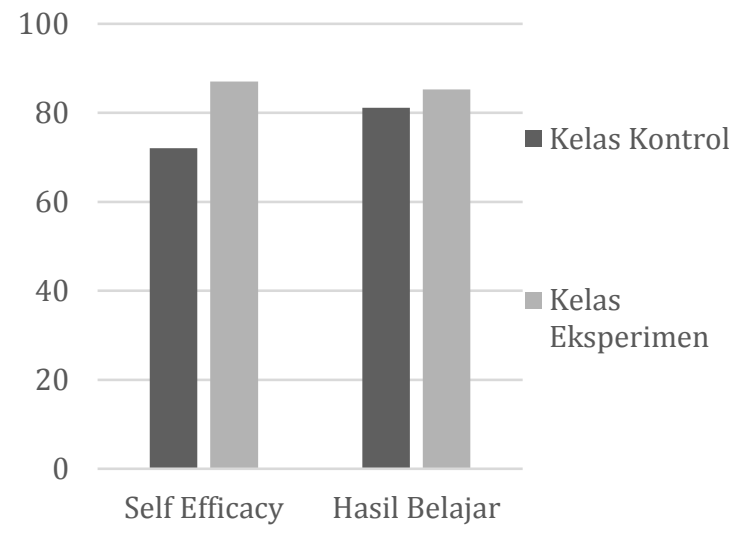

Gambar 2. Peningkatan Hasil Belajar

Peningkatan hasil belajar dengan model eliciting activities dikarenakan model ini dapat menolong siswa agar lebih antusias saat proses pemecahan masalah dalam proses pembelajaran [9][14]. Hal ini sejalan dengan penelitian [12] menyimpulkan bahwa model eliciting activities mampu meningkatkan hasil belajar peserta didik, dikarenakan peserta didik sudah terbiasa menghadapi situasi pada kehidupan nyata.

Hubungan antara self efficacy dan hasil belajar di tunjukkan dari koefisien korelasi (r). Hubungan self efficacy dan hasil belajar didapatkan bahwa nilai $r_{\text {hitung }}>r_{\text {tabel }}$ yaitu 0,8079 $>0,392$ yang menyimpulkan bahwa adanya hubungan positif antara self efficacy dengan hasil belajar, berada pada kategori korelasi sangat kuat. Hubungan self efficacy ataupun emosional untuk meningkatkan self efficacy (keyakinan diri) peserta didik [7]. Dorongan ini bertujuan agar perkembangan self efficacy (keyakinan diri) mencapai tingkat yang optimal [6]. Sedangkan

dari pembelajaran sebelum-sebelumnya. Penemuan ini sejalan dengan penelitian [9] menyimpulkan bahwa model pembelajaran berbasis pemberian permasalahan mampu meningkatkan kemampuan self efficacy (keyakinan diri) peserta didik.

dan hasil belajar peserta didik dapat dilihat pada Gambar 3.

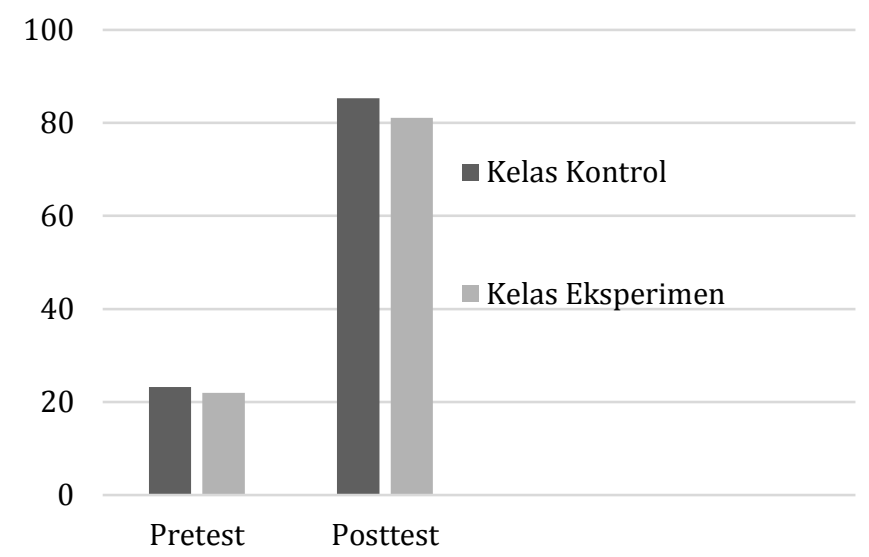

Gambar 3 Korelasi Self Efficacy dan Hasil Belajar

Self efficacy memiliki hubungan positif terhadap hasil belajar peserta didik. Model eliciting activities ini mendorong untuk mengembangkan self efficacy (keyakinan diri), self efficacy yang terbentuk akan meningkatkan hasil belajar peserta didik. Self efficacy (keyakinan diri) yang optimal dalam diri akan membuat peserta didik menjadi termotivasi dan tidak ragu lagi dengan solusi yang ditawarkan oleh peserta didik. Self efficacy berpengaruh terhadap pola pikir dan reaksi emosional, peserta didik yang mempunyai self efficacy (keyakinan diri) yang tinggi akan mampu menghadapi permasalahan-permasalahan yang ada.

\section{KESIMPULAN}

Model eliciting activities mampu meningkatkan self efficcay (keyakinan diri) dan hasil belajar siswa, memiliki hubungan yang lebih kuat terhadap self efficacy (keyakinan diri) dan hasil belajar peserta didik. Kemampuan self efficacy (keyakinan diri) dan hasil belajar siswa dengan model eliciting activities sangat optimal dibandingkan kelas yang mengaplikasikan pendekatan saintifik 


\section{DAFTAR PUSTAKA}

[1] Trianto, I. B. (2014). Mendesain model pembelajaran inovatif, progresif, dan kontekstual. Jakarta: Prenadamedia Group.

[2] Chamberlin, S. A., \& Moon, S. M. (2008). How does the problem based learning approach compare to the model-eliciting activity approach in mathematics. International Journal for Mathematics Teaching and Learning, 9(3), 78-105.

[3] Dimyati, M. (2013). Belajar \& Pembelajaran. Jakarta: Rineka Cipta.

[4] Hamilton, E., Lesh, R., Lester, F. R. A. N. K., \& Brilleslyper, M. (2008). Model-eliciting activities (MEAs) as a bridge between engineering education research and mathematics education research. Advances in Engineering Education, 1(2), n2.

[5] Hanifah, H. (2016). Penerapan Pembelajaran Model Eliciting Activities (MEA) dengan Pendekatan Saintifik untuk Meningkatkan Kemampuan Representasi Matematis Siswa. Kreano, Jurnal Matematika KreatifInovatif, 6(2), 191-198.

[6] Noviandari, H., \& Kawakib, J. (2016). Teknik Cognitive Restructuring untuk Meningkatkan Self Efficacy Belajar Siswa. Jurnal Psikologi: Jurnal Ilmiah Fakultas Psikologi Universitas Yudharta Pasuruan, 3(2), 76-86.
[7] Jaenudin, U., \& Hambali, A. (2015). TeoriTeori Kepribadian. Bandung: Pustaka Setia.

[8] No, P. M. P. N. (23). Tahun 2006 tentang Standar Kompetensi Lulusan untuk Satuan Pendidikan Dasar dan Menengah. Jakarta: Depdiknas.

[9] Reflina, R. (2018). KAITAN PEMBELAJARAN BERBASIS MASALAH DENGAN KEMAMPUAN SELF-EFFICACY SISWA. AXIOM: Jurnal Pendidikan dan Matematika, 7(1).

[10] Sudjana, N. (1995). Penilaian hasil proses belajar mengajar.

[11]Bandung, R. D., \& Fathoni, A. A. (2012). Alfabeta. Sujarweni, V dan Poly Endrayanto.

[12] Setiadi, D. (2014). Model Pembelajaran Berbasis Peningkatan Literasi Sains dan Implementasinya dalam Kurikulum Sains SMP 2013. Jurnal Pijar Mipa, 9(1).

[13] Amalia, Y., Duskri, M., \& Ahmad, A. (2015). Penerapan model eliciting activities untuk meningkatkan kemampuan berpikir kreatif matematis dan self confidence siswa SMA. Jurnal Didaktik Matematika, 2(2).

[14] Ernawati, T. (2016). Implementasi Scientific Approach Pada Outdoor Learning Untuk Meningkatkan Motivasi Belajar Mahasiswa Pendidikan IPA. Jurnal Pijar Mipa, 11(1). 